Revista Digital Universitaria

Vol. 23, Núm. 1, enero-febrero 2022

\title{
Mirando nuestro camino, reflexiones sobre el modelo SUAyED
}

\author{
Ana I. Tsutsumi
}

\begin{abstract}
Resumen
Una mirada retrospectiva del Sistema de Universidad Abierta y Educación a Distancia (suAyED) de la Universidad Nacional Autónoma de México (UNAM) permite revisar los principales atributos con los que nació esta modalidad académica en la Facultad de Filosofía y Letras. Por medio de una reflexión crítica se comentan sus diferencias con otras modalidades y se pone énfasis en la experiencia que se tiene para el caso de la Licenciatura en Lengua y Literaturas Hispánicas. Se destacan, por ejemplo, aspectos como el perfil de los estudiantes, el concepto de aula invertida y la pluralidad de los espacios académicos, en los que convergen docentes y estudiantes. En un contexto marcado por la crisis sanitaria derivada de la pandemia, se mencionan los retos que se tienen en torno a la evaluación del aprendizaje.
\end{abstract}

Palabras clave: comunidad suAyEd, aula invertida, modelo híbrido, exámenes digitales.

\section{LOOKING OUR PATH, REFLECTIONS ON THE SUAYED MODEL}

\begin{abstract}
A retrospective look at the Open University System and Distance Education (SUAYED) of the National Autonomous University of Mexico (UNAM) allows us to review the main attributes with which this academic modality was created in the Faculty of Philosophy and Letters. Through a critical reflection, its differences with other modalities are highlighted, and emphasis is placed on the experience obtained for case of the bachelor in Hispanic Language and Literatures, in which, for example, aspects such as the profile of the students, the concept of the flipped classroom and the plurality of academic spaces, in which teachers and students converge, stand out. In a context marked by the health crisis derived from the pandemic, the challenges that exist around the evaluation of learning are mentioned.
\end{abstract}

Keywords: SUAYED community, flipped classroom, hybrid model, digital testing. 
Profesora de Carrera con especialidad en Filología Hispánica, adscrita al Departamento de Letras Hispánicas FFyL, UNAM. Docente en la licenciatura en Escritura Creativa y Literatura en la Universidad del Claustro de Sor Juana. Fue docente de la Maestría en Comunicación y Tecnología Educativa del ILCE. Tiene estudios de doctorado en lingüística por El Colegio de México. Ha cursado Diversos Diplomados en el área de Gestión del Conocimiento en Ambientes Educativos Asistidos por TIC (CUAED/UNAM). Ha dirigido más de 20 tesis de licenciatura y ha sido parte de sínodos de licenciatura y maestría. Asesora académica de cursos de actualización docente para bachillerato en el área de Escritura y Lectura flAcso. Diseño del curso "Programa Curricular de Formación Inicial de Evaluadores de Desempeño Docente" Instituto Nacional para la Evaluación de la Educación (INEE). Diseño de cursos de Escritura académica y Pensamiento Crítico para la maestría мстуE del ILCE. Además de participar en cuerpos colegiados como Consejera Técnica del EXANı del Ceneval: Ha participado en distintos proyectos de investigación (entre Ios que se encuentran el proyecto Amoxcalli, coord. por Thomas Smith Stark. CIESAS/ Conacyt. Proyecto de Investigación Gramática Histórica a cargo de Concepción Company, Catálogo de Textos Marginados Novohispanos en el Archivo General de la Nación, proyecto de fonca y El Colegio de México). referirnos a la propuesta de un modelo innovador en Humanidades, que a fines de los setenta propuso la creación de seis licenciaturas en el Sistema de Universidad Abierta en la Facultad de Filosofía y Letras, y hace más de diez años, dos licenciaturas en el Sistema de Educación a Distancia (Mirador Universitario, 2015). El reto ha sido consolidar el suayed en nuestra Facultad, como un espacio en el que confluyen propuestas innovadoras.

¿Qué hace diferente al suAyed del sistema presencial? ¿Su comunidad, el modelo educativo, los objetivos que persigue, los materiales de trabajo (sus guías de estudio)? Si la respuesta es el conjunto de todos estos aspectos, entonces, estaremos generalizando, pues todo modelo de enseñanza-aprendizaje los posee. Por ello, decir que el suAyed es único sería caer en una "excesiva estima"1. No obstante, sí podemos reflexionar de qué manera influye este prisma. Fue en el año 2011 que nuestra licenciatura participó en la serie Mirador Universitario, de la entonces CUAED (ahora cUAIEEd; Mirador Universitario, 2011). Varios capítulos plasmaron los acercamientos acerca de las áreas de conocimiento de los profesores que forman nuestra cátedra. Sin embargo, dejamos en el tintero hablar de nuestra comunidad. Hoy, después de una década, me gustaría tratar los puntos de encuentro que tienen nuestras y nuestros estudiantes. 
"Mirando nuestro camino, reflexiones sobre el modelo SUAyED"

Ana I. Tsutsumi

Vol. 23, Núm. 1, enero-febrero 2022

Revista Digital Universitaria

\section{Entre la especificidad y la pluralidad: nuestras textualidades}

Nuestros grupos son plurales, y no nos referimos a que la unAm está conformada por un sinnúmero de microcosmos, sino a que nuestra comunidad de estudiantes en letras suayed tiene cualidades que la enriquecen y la conforman. Después de una larga historia académica, nuestras y nuestros estudiantes deciden ingresar a la licenciatura, ya sea por el amor a la lectura, porque desean profundizar en las letras o porque buscan formalizar sus conocimientos. Nos suelen comentar que estudiar en el Sistema de Universidad Abierta (sUA) es una oportunidad de compaginar la vida laboral y académica, de obtener conocimientos en un ámbito en que existen interlocutores valiosos, que les permiten quitarse prejuicios. Llegan con esa curiosidad que genera incertidumbre, pues en algunos casos han pasado varios años desde que pisaron las aulas y en otros llevan a cuestas estudios de posgrado en áreas disciplinares distintas.

Así, al entrar al espacio SUA, en esos momentos en que se siguen redefiniendo para concretar sus estudios, se encuentran con el aula invertida, con el estudio independiente, con el trabajo colaborativo, con el pensamiento crítico: "viejos conocidos para el SUAyED". ${ }^{2}$ Nuestras y nuestros estudiantes se forman a su propio ritmo (mediante las guías elaboradas por los distintos comités académicos), recuperan materiales de apoyo (videos, podcast, presentaciones, etcétera), y en las sesiones semanales comparten sus reflexiones y dudas. ¿Quién emite el mejor comentario sobre una novela o un cuento? No es trascendente, lo que importa es que pueden esos mundos ficcionales.

\section{La elaboración: el SUAyED en estos tiempos}

${ }^{2}$ Inevitablemente tengo que recurrir a mi historia para hablar del suayed, hace más de 17 años me invitaron a dar clases en la fFyL en el suA. Esta generosa oportunidad coincidió con que en ese momento empezaba a formarme curricularmente en el ámbito de la educación a distancia y coordinaba una maestría cuyo modelo era híbrido: cada lunes teníamos sesiones frente a grupo, que se transmitían por videostreaming en plataforma y por la red EDUSAT.

Además, contábamos con el aula virtual para que las y los estudiantes pudieran tener los materiales y realizar actividades. Mi camino había empezado: mi reto era llevar esa experiencia a las aulas de sua en mi facultad.
En las innumerables conferencias y mesas acerca de la educación durante esta crisis sanitaria, se comenta que, para hacer frente a la nueva virtualidad, "los docentes se apropiaron de las plataformas de aprendizaje, de las aplicaciones para generar actividades; en tanto que los estudiantes tomaron más control para la gestión de sus herramientas de trabajo, en particular, del uso del internet y de las computadoras; mientras que el personal administrativo también tuvo que reinventarse para tener una gestión a distancia". Es decir, se trasladó el espacio físico al espacio virtual, con todas las dificultades que implica un cambio, también con las oportunidades que surgen en una crisis.

A estas transformaciones ha de sumarse el uso creciente de métodos y modelos acordes. Por ejemplo, cuando nos detenemos a reflexionar acerca de la evaluación (uno de los aspectos formativos y necesarios que da cauce a la educación) vemos que surgen las limitaciones, pero también las posibilidades. Antes de la pandemia, uno de los aspectos de la evaluación, el de los exámenes, consistía en tener a las y los estudiantes en un salón y entregarles un listado de reactivos o preguntas de respuesta abierta, que debían resolver en un período 
determinado. Así se documentaba el proceso y existía cierta vigilancia visual por parte de los docentes que otorgaba confiabilidad.

Sin embargo, con la pandemia el formato de examen no es factible, ya que no se puede realizar el monitoreo y vigilancia al momento de realizarlo. Por lo anterior, en suA se puso énfasis en la evaluación formativa: nos concentramos en tareas o actividades que implican el trabajo colaborativo y cooperativo -el espacio físico se borró, no hay pretexto para lograr coincidir en horarios-, el aprendizaje basado en proyectos (ABP), y el basado en solución de problemas.

Asimismo, en este contexto, varios docentes usaron una estrategia de examinación que implica entregar, mediante un formulario, un conjunto de preguntas que tienen un grado mayor de dificultad y cuyo objetivo es demostrar que el estudiante es capaz de responderlas de manera individual, sin importar

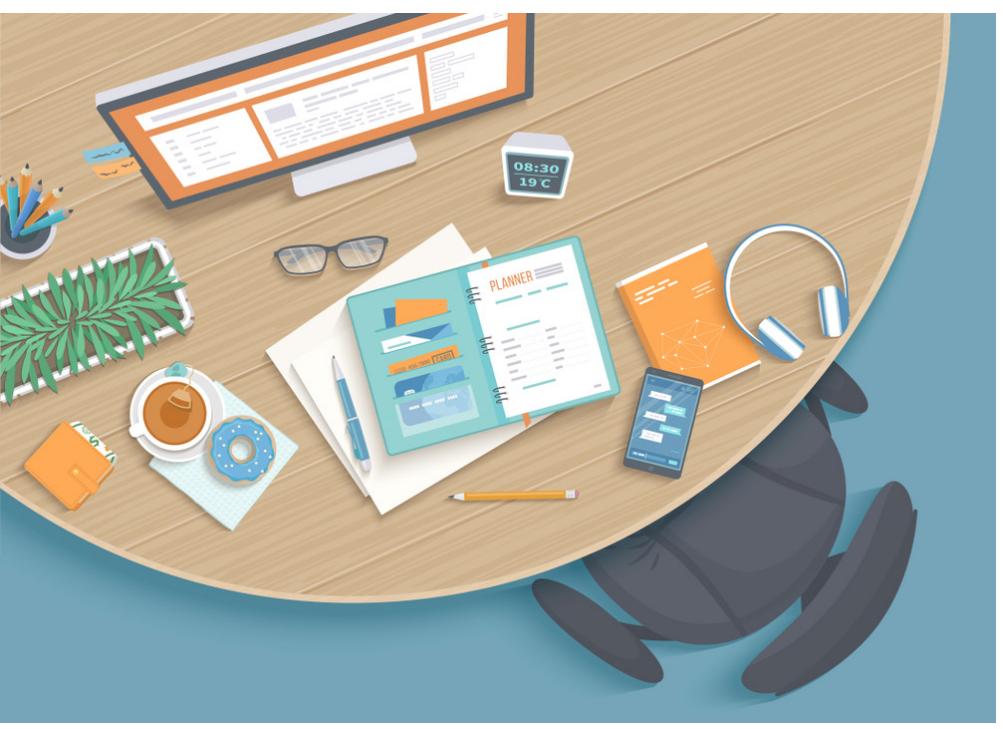
que pueda consultar fuentes de información alternas, es decir, es un examen a libro abierto. Sin duda, un aspecto que se deberá trabajar en la era pospandemia deberá ser la factibilidad y el uso de los exámenes digitales, que se validen de manera confiable, utilizando todos los recursos electrónicos necesarios.

Ahora bien, en el suAyed de la fFy se pone de manifiesto la importancia de comparar modelos y experiencias, para tomar decisiones acerca del rumbo hacia dónde queremos orientar los esfuerzos: un modelo híbrido. Aquél que en vez de difuminar las fronteras entre un sistema presencial y un Sistema de Universidad Abierta y de Educación a Distancia, reconozca las especificidades de cada uno y el camino trazado; que no se adjudique la autoría o el uso de tal o cual herramienta, sino que converja en su pluralidad y se adecúe a su comunidad.

Una propuesta como el suAyEd se fundamenta en necesidades de educación reales, dinámicas, y reconoce la tendencia mundial hacia las modalidades híbridas y virtuales. Celebramos este aniversario, integrando los aprendizajes de toda la comunidad, para actualizar nuestra práctica educativa.

\section{Referencias}

* Mirador Universitario. (2011). ¿En qué trabaja un egresado de Lengua y Literaturas hispánicas? [Video]. UNAM-CUAIEED. https://mediacampus.cuaieed.unam.mx/ node/1900 
* Mirador Universitario. (2015). Los estudios de arte escénico y los estudios en el sistema abierto y a distancia [Video]. UnAM-CUAIEED. https://mediacampus.cuaieed. unam.mx/node/5169

\section{Cómo CITAR ESTE ARTículo}

* Tsutsumi, Ana, I. (2022, enero-febrero). Mirando nuestro camino, reflexiones sobre el modelo suAyED. Revista Digital Universitaria (RDU), 23(1). http://doi.org/10.22201/ cuaieed.16076079e.2022.23.1.13 